\title{
Un simple grano en la nariz
}

\section{A simple pimple on the nose}

\author{
Sergio Gabriel Carbia ${ }^{1}$ y Roberto Glorio ${ }^{2}$
}

\author{
1 Director de la Carrera de Especialistas en Dermatología \\ 2 Profesor Regular Adjunto \\ Universidad de Buenos Aires, Ciudad Autónoma de Buenos \\ Aires, Argentina
}

Dermatol. Argent. 2021, 27 (2): 83-84
Contacto del autor: Sergio Gabriel Carbia

E-mail: sergiocarbia67@gmail.com

Fecha de trabajo recibido: 24/12/2020

Fecha de trabajo aceptado: 29/1/2021

Conflicto de interés: los autores declaran que no existe conflicto de interés.
A mi nunca se me ocurriria suicidarme por un simple grano en la nariz, por supuesto, no soy tan coqueto como hipocondríaco, el problema es que sea el grano el que decida suicidarse de repente, porque entonces a lo mejor nos moriremos los dos. Hasta ahora no habia escrito sobre mi grano en este diario, primero porque no pensaba que fuese a durarme tanto tiempo, y segundo porque una de las razones de ser de este diario es fabricarme una leyenda de glamour acendrado, que diría un aprendiz de Rimbaud o similar. Vamos, que se trata de hacer de mi un personaje de interés turístico y repercusión social, con vistas a postularme para el Nobel o para la Medalla de las Bellas Artes, que me da lo mismo, y en ese sentido, en fin, un escritor con un grano en la nariz difícilmente puede convertirse en un escritor de leyenda. Ni Hemingway sería el mismo con un grano en la nariz. Sin embargo, parece que la cosa se está agravando de manera alarmante y me temo que ya no puedo seguir ocultándolo por más tiempo. Se trata de un grano con espiritu revolucionario, es decir, que no tiene pinta de ser un grano normal tipo acné juvenil y tal, sino más bien que parece un herpe, un hongo o algo asi, aunque yo claro, a todo el que pregunta aprovecho para soltarle la broma de que a lo mejor es cáncer. De modo que me paso los dias pellizcándome el grano y hurgando en él con la punta de un compás, con la nariz a dos dedos del espejo. A veces me siento como un cirujano operándose a si mismo a corazón abierto y sin anestesia. Pero hasta ahora no he conseguido arreglar nada, porque el grano suelta una lagrimilla de pus lechecino y otra de sangre $y$

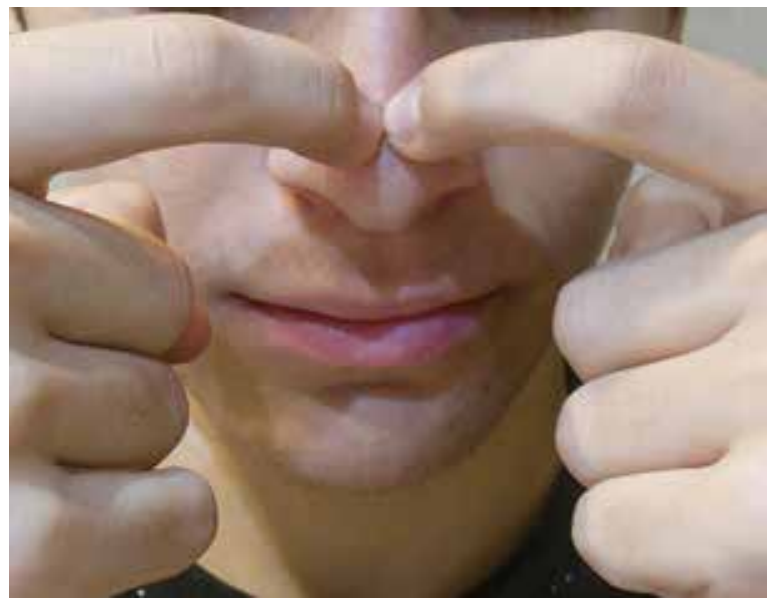

al día siguiente tengo una pequeña costra y más pus enquistado señalándome desde el espejo. Hay leprosos que dan menos grima que mi grano. Al menos cuando me sueno los mocos no me molesta. Es como si en la intimidad no le costase al grano mantener la compostura. En cambio, en la calle el cabrón saca pecho, hasta el punto de que cuando alguien me saluda ya dudo si me está saludando a mi o al grano.

\section{GERMÁN SAN NICASIO (ESPAÑA, 1978)}

Escritor y pintor madrileńo que, tras dejar y retomar sus estudios de arquitectura, hasta finalmente abandonarlos, se dedicó a las exposiciones de pintura y a una promisoria carrera literaria. Su primera novela Verde pañuelo (2003) le valió el premio de la Fundación Joselito, a la que siguió Mejor guion adaptado (2006) y 
las novelas La cárcel de Jackson Pollock (2010) y Diario de un escritor delgado (2011), con solo 5 meses de separación entre sus apariciones. Posteriormente, dio a la luz Una sardina en una copa de champán (2015).

La novela Diario de un escritor delgado gira en torno a la vida de un hombre extrańo que observa la vida desde el arco iris del optimismo beligerante e ingenuo hasta la decepción más profunda. A pesar de estar inmerso en su mundo privado, al personaje no se le escapa de su radar ninguna situación de la vida cotidiana, por más sencilla que parezca, que le permita expresar su opinión, en un lenguaje primitivo, verborrágico y, por momentos, agresivo y chocante. Mientras monologa en forma continua sobre sus andanzas y chismes íntimos, aprovecha para hacer una crítica del mundo mediocre y ruin que lo rodea, disparando contra todo lo que encuentra a su paso sin tomar conciencia de las consecuencias.

En sus páginas, el autor menciona a la hormona de la literatura, bajo el nombre ficticio de "literatona", una suerte de testosterona literaria que regula las ga- nas de escribir, "de follar" con las palabras, al decir de Francisco Umbral, y que marca la diferencia entre los escritores de verdad y los que no lo son.

En una entrevista ha dicho: "El mundo no es una mierda, aunque hay mucha mierda en el mundo. Pero le diré que yo uso la escritura a modo de desahogo: escribo cuando no me encuentro bien y por eso mi libro tiene ese aire pesimista y negativo. Digamos que el folio en blanco es para mí un vertedero emocional" y "No hay que tirar la toalla aunque las cosas se pongan cada vez más difíciles porque, en el fondo, eso es lo que le da la gracia al asunto. Y también aprendí a conocer a la gente: hay personas que parecen muy desagradables a primera vista, pero que luego se entregan contigo; en cambio, otras son todo buenas palabras... y en eso se quedan".

\section{BIBLIOGRAFÍA}

San Nicasio G. Diario de un escritor delgado, 1. ${ }^{\mathrm{a}}$ ed. Editorial Eutelecquia, Madrid, 2011, p. 124.

\section{DERMATÓLOGOS JÓVENES}

\section{Mitos y verdades. VACUNA CONTRA EL VIRUS DEL PAPILOMA HUMANO}

\section{Tatiana Giselle Nógalo ${ }^{1}$, Laura Cantú Parra² y María Noelia Andrade ${ }^{3}$ \\ ${ }^{1}$ Médica Rotante, Hospital Presidente Dr. Nicolás Avellaneda, San Miguel de Tucumán, Provincia de Tucumán, Argentina \\ 2 Jefa de Residentes de Dermatología, Hospital Luis C. Lagomaggiore, Mendoza, Provincia de Mendoza, Argentina \\ 3 Jefa de Residentes de Dermatología, Clínica Universitaria Reina Fabiola, Córdoba, Provincia de Córdoba Argentina}

\section{ENUNCIADOS}

1. "La vacuna tetravalente contra el VPH es una opción terapéutica potencial para el tratamiento de verrugas cutáneas, papilomatosis respiratoria recurrente y carcinomas de células escamosas".

2. "Se desestima la vacunación en el niño varón por la baja carga de enfermedades asociadas al virus".

3. “El esquema de vacunación contra el virus del papiloma humano (VPH) en inmunodeprimidos es igual que en inmunocompetentes".

\section{RESOLUCIÓN}

1. VERDAD. Según un artículo publicado en 2020 en Journal of the American Academy of Dermatology, la utilización de la vacuna contra el VPH, con su consecuente estimulación del sistema inmunitario, es una alternativa de gran interés para el tratamiento de las patologías cutáneas y mucosas asociadas a este virus. Se propone la protección contra múltiples cepas luego de la vacunación por los efectos de reacción cruzada. La mayoría de los pacientes con verrugas cutáneas, papilomatosis respiratoria y carcinomas intraepiteliales experimentaron una remisión clínica al finalizar el tratamiento. Si bien la indicación actual de esta vacuna es preventiva, la respuesta evidenciada en estos pacientes justifica la realización de ensayos clínicos multicéntricos para evaluar la eficacia a largo plazo

\section{BIBLIOGRAFÍA}

1. Pham CT, Juhasz M, Sung CT, Mesinkovska NA. The human papillomavirus vaccine as a treatment for human papillomavirus-related dysplastic and neoplastic conditions: A literature review. J Am Acad Dermatol 2020;82:202-212.

2. MITO. Según el registro epidemiológico de la OMS publicado en 2017, se estima que la prevalencia de infección por el VPH es más alta en los varones que en las mujeres ${ }^{1}$. Existen genotipos de VPH oncogénicos, en especial el VPH 16, causantes de un porcentaje variable de cánceres de la cavidad bucal, la faringe y el ano. Estos tipos de neoplasias asociadas al virus son más frecuentes en el hombre que en la mujer². Por ello, la vacunación en los niños preadolescentes está indicada para la protección individual frente a estas enfermedades que afectan en mayor parte a este grupo y como estrategia para disminuir la transmisión a las mujeres. El agente de salud debe promover y recomendar activamente la vacunación de los varones preadolescentes.

\section{BIBLIOGRAFÍA}

1. Human papillomavirus vaccines: WHO position paper, May 2017. Wkly Epidemiol Rec 2017;92:241-268.

2. Brotons Agulló M, Serraro Carro B. Vacunación frente al virus del papiloma humano (VPH) y adolescencia. Pediatr Integral 2020;24:468.
3. MITO. La vacuna tetravalente está incorporada al Calendario Nacional de Inmunización de Argentina para niñas y niños de 11 años de edad con el esquema 0 y 6 meses. Los pacientes inmunosuprimidos presentan mayor persistencia de la infección por el VPH. Todos los cánceres relacionados con este virus se presentan en mayores tasas en la población que vive con el virus de la inmunodeficiencia humana (VIH) y en los trasplantados de órganos sólidos y células hematopoyéticas que en la población sin estas patologías. El Programa Nacional de Control de Enfermedades Inmunoprevenibles provee la vacuna contra el VPH tetravalente con tres dosis $(0,2$ y 6 meses) para varones y mujeres de entre 11 y 26 años con VIHy quienes hayan sido trasplantados (órganos sólidos 0 células hematopoyéticas). Además, se recomienda vacunar a las personas de entre 27 y 45 años con condiciones de base que las pueden hacer más vulnerables a la infección por VPH, como consumo de inmunosupresores 0 inmunoterapia, diabetes mellitus, enfermedades autoinmunes como artritis reumatoide o lupus, entre otras'.

BIBLIOGRAFÍA

1. Katz N, Vázquez E. Vacuna contra el virus del papiloma humano (VPH). Recomendaciones sobre vacunas. Actualización 2019. Sociedad Argentina de Infectología. Disponible en: https://www.sadi.org.ar/documentos/guias-recomendaciones-y-consensos/item/797-recomendaciones-sobre-vacunas-actualizacion-2019. [Consulta: abril 2021]. 